unlikely to diminish the benefit of antihypertensive drugs in preventing stroke, as suggested by Waller et $a l,{ }^{18}$ as little reduction in cardiovascular disease resulted from lowering diastolic blood pressure below about $95 \mathrm{~mm} \mathrm{Hg}$ in the Australian mild hypertension study, ${ }^{11}$ the international prospective primary prevention study in hypertension, ${ }^{10}$ and the Medical Research Council's mild hypertension study (MRC Working Party, 11th scientific meeting of the International Society of Hypertension, Heidelberg, 1986). Until more information is available particular caution is appropriate when treating hypertension in elderly patients. Mattila $e t$ al showed that over five years of follow up the greatest mortality in patients aged 84 and over was observed in those with the lowest systolic and diastolic blood pressures (not related to poor health) and that the lowest was in patients with a systolic blood pressure of $160 \mathrm{~mm} \mathrm{Hg}$ or more and diastolic blood pressures of $90 \mathrm{~mm} \mathrm{Hg}$ or more. ${ }^{27}$ Patients aged 60-79 who have isolated systolic hypertension (phase $\mathrm{V}$ diastolic blood pressure less than $90 \mathrm{~mm} \mathrm{Hg}$ ) may be harmed by treatment. ${ }^{16}$

Care should be taken in extrapolating data on the J curve derived from hypertensive patients with ischaemia to normotensive patients with ischaemia as the normotensive patients may have better coronary flow reserve in the absence of left ventricular hypertrophy ${ }^{2829}$ and the autoregulatory curve relating coronary flow to pressure is likely to be set at a lower level than in patients with hypertension - that is, the $\mathrm{J}$ point may be lower.

1 Lew EA. High blood pressure, other risk factors and longevity: the insurance viewpoint. Am f Med 1973;55:281-94.

2 Kannel WB. Role of blood pressure in cardiovascular morbidity and mortality. Prog Cardiovasc Dis 1974;17:5-23.

3 Anderson TW. Re-examination of some of the Framingham blood-pressure data. Lancet 1978;ii:1139-41.

4 McGee D, Gordon T. The Framingham study. In: Kannel WB, Gordon T, eds. An epidemiological investigation of cardiovascular disease. Section 31 . Washington, DC: United States Government Printing Office, 1976 DHEW publication No 76-1083.)

5 Stewart IMcDG. Long-term observations on high blood pressure presenting in fit young men. Lancet 1971;i:355-8.

6 Stewart IMcDG. Hypertension and myocardial infarction. Br Med $\mathcal{f}$ 1974; 251.

7 Stewart IMcDG. Relation of reduction in pressure to first myocardial infarction in patients receiving treatment for severe hypertension. Lance 1979;i:861-5.

8 Medical Research Council Working Party. MRC trial of treatment of mild hypertension: principal results. Br Med f 1985;291:97-104

9 Management Committee of the Australian Therapeutic Trial in Mild Hypertension. The Australian therapeutic trial in mild hypertension. Lance 1980; i: 1261-7.

10 IPPPSH Collaborative Group. Cardiovascular risk and risk factors in a randomized trial of treatment based on the beta-blocker oxprenolol: the international prospective primary prevention study in hypertension (IPPPSH). 3 Hypertension 1985;3:379-92.

11 Management Committee of the Australian Therapeutic Trial in Mild Hypertension. Untreated mild hypertension. Lancet 1982;i:185-91.

12 Medical Research Council Working Party. Stroke and coronary heart disease in mild hypertension: risk factors and the value of treatment. Br Med $\mathcal{J}$ 1988;296:1565-70.

13 Cruickshank JM, Thorp JM, Zacharias FJ. Benefits and potential harm of lowering high blood pressure. Lancet 1987; i:581-4.

14 Wilhelmsen $\mathrm{L}$, Berglund $\mathrm{G}$, Elmfeldt $\mathrm{D}$, et al. Beta-blockers versus diuretics in hypertensive men: main results from the HAPPHY trial. $\mathcal{f}$ Hypertension 1987;5:561-72.

15 Samuelsson O, Wilhelmsen L, Andersson OK, Pennert K, Berglund G Cardiovascular morbidity in relation to change in blood pressure and serum cholesterol levels in treated hypertension: results from the primary prevention trial in Göteborg, Sweden. FAMA 1987;258:1768-76.

16 Coope J, Warrender TS. Randomised trial of treatment of hypertension in elderly patients in primary care. Br Med 7 1986;293:1145-51.

17 Coope J, Warrender TS. Lowering blood pressure. Lancet 1987;ii:518.

18 Waller PC, Isles CG, Lever AF, Murray GD, McInnes GT. Does therapeutic reduction of diastolic blood pressure cause death from coronary hear disease? I Human Hypertension 1988;2:7-10.

19 Fletcher AE, Beevers DG, Bulpitt CJ, et al. The relationship between a low treated blood pressure and IHD mortality: a report from the DHSS treated blood pressure and IHD mortality: a report from the DHSS hypertension

20 Sleight P. Blood pressures, hearts, and U-shaped curves. Lancet 1988;i:235.

21 Buffington CW. Hemodynamic determinants of ischemic myocardial dysfunction in the presence of coronary stenosis in dogs. Anesthesiology 1985;63:651 62 .

22 Klocke FJ. Measurements of coronary flow reserve: defining pathophysiology versus making decisions about patient care. Circulation 1987;76:1183-9.

23 Cruickshank JM, Thorp JM, Zacharias FJ. Heart attacks and lowering of blood pressure. Lancet 1987; ;:1154.

24 Strandgaard S, Haunsø S. Why does antihypertensive treatment prevent stroke but not myocardial infarction? Lancet 1987;ii:658-60.

25 Tijssen JGP, Simoons ML, Lubsen J. Review of other trials. Eur Heart $\mathcal{f}$ 1987;8(suppl H):87-98.

26 Holland Interuniversity Nifedipine/Metoprolol Trial Research Group. Early treatment of unstable angina in the coronary care unit: a randomised, double-blind, placebo controlled comparison of recurrent ischaemia in patients treated with nifedipine or metoprolol or both. Br Heart patients treated

27 Mattila K, Haavisto M, Rajala S, Heikinheimo R. Blood pressure and five year survival in the very old. Br Med $\mathcal{F} 1988 ; 296: 887-9$.

28 Pepi M, Alimento M, Maltagliati A, Guazzi MD. Cardiac hypertrophy in hypertension: repolarization abnormalities elicited by rapid lowering of pressure. Hypertension 1988;11:84-91.

29 Dellsperger KC, Marcus ML. The effects of pressure-induced cardiac hypertrophy on the functional capacity of the coronary circulation. Am $\mathcal{J}$ Hypertension 1988;1:200-7.

(Accepted 10 August 1988)

\title{
Babies with spina bifida treated without surgery: parents' views on home versus hospital care
}

\author{
Eileen Delight, Janet Goodall
}

Association for Spina Bifida and Hydrocephalus, London WC1H OEP

Eileen Delight, BSC, research worker

\section{North Staffordshire}

Hospital Centre, Stoke on

Trent, Staffordshire

Janet Goodall, FRCPED,

consultant paediatrician

Correspondence to:

Dr Goodall

\begin{abstract}
From 1971 to 1981 , 98 babies born with meningomyelocoele at the North Staffordshire Hospital Centre's district maternity hospital, were thought not suitable for surgery. Sixty three survived for more than one week. Over the period the hospital's policy changed: initially all such babies were kept in hospital, but later parents were given the choice of taking their baby home for palliative and terminal care. In an attempt to determine parents' views on the care of their baby the parents of 44 of the babies who survived to one week were traced in 1985-6, five to 14 years later; 80 of them were asked how they felt about the lives and deaths of their babies. Eighteen babies had been taken home, and they had lived longer than the 26 who had been cared for in hospital. Parents whose baby had remained in hospital were sadder than those who had taken their baby home when they looked back at their experiences,
\end{abstract}

and they also considered that their baby's life had been of poor quality. Most of those who had taken their baby home had a more positive view of their child's life.

The figures suggest that the bereavement process after a baby's death is longer than has been thought, but despite residual sadness just over half of the parents interviewed thought that something positive had come out of their experience.

\section{Introduction}

From 1971 to 1975 babies with a meningomyelocoele who were considered unsuitable for an operation were kept in hospital throughout their lives. By 1981 over $90 \%$ of such babies who survived for more than a week received much of their palliative and terminal care at home, though some families still returned for hospital support when the baby was dying. We 
analysed the effect of these changes in $1984,{ }^{1}$ excluding babies who underwent late operations. Altogether 63 out of 98 babies survived for more than one week. In 1985-6 we followed up 44 of the 63 original families, five to 14 years after the baby's birth, to determine what parents thought about their baby's life, comparing hospital and home care. The interviewer (ED) had not taken part in the early care of these families.

\section{Methods}

An introductory letter was taken to each family by their health visitor inviting their participation. Of the original 63 families, nine could not be traced and nine refused to take part, which left the year 1971 unrepresented. One family was not approached as the parents had announced the baby as stillborn. Six parents were not available because of death or separation. Of the 82 parents who agreed to be interviewed, two fathers defaulted (they were "still too upset" to be seen). One divorced father chose to be interviewed at the hospital, but all the other parents were interviewed with a semistructured questionnaire at home.

The parents were asked about events around the birth, how the news had been broken, how much interaction had been encouraged with the child both in hospital and at home, and the helpfulness of the extended family and other supporting services. They were also asked about the baby's enjoyment of life, use of treatment, any need for readmission, and the manner and place of death. The reactions of parents and wider family were noted, and the parental grief at the time of the interview was rated according to a five point score from $1=$ sad/angry to $5=$ happy/serene. Much of the information given was anecdotal, and the figures were too small for statistical analysis.

Ethical approval was granted by the hospital centre's medical ethics committee.

\section{Results}

\section{BREAKING THE BAD NEWS}

The father had been present at the delivery of 17 of TABLE II-Quality of life of 44 babies with spina bifida in hospital and at home as perceived by their parents

\begin{tabular}{lcc}
\hline $\begin{array}{l}\text { Quality } \\
\text { of life }\end{array}$ & $\begin{array}{c}\text { Hospital } \\
(\mathrm{n}=26)\end{array}$ & $\begin{array}{c}\text { Home } \\
(\mathrm{n}=18)\end{array}$ \\
\hline Good & 8 & 18 \\
Mostly good & 8 & 16 \\
Mostly bad & 1 & 1 \\
"Rotten" & 8 & \\
No life at all & 16 & \\
Don't know & 4 & \\
\hline Total & 45 & 35 \\
\hline
\end{tabular}

the 44 babies, but the parents of only 15 babies recalled that they had been told immediately that something was wrong. In 12 cases one partner had told the news to the other, and in over two thirds the baby had not been present when the bad news was broken. About half the parents were unhappy about the way they had been told, and complained of either inadequate time for questions or lack of sympathy in the telling. Over a third were still unhappy about their limited understanding of the decision not to operate, and 18 spontaneously expressed guilt about their child's handicap.

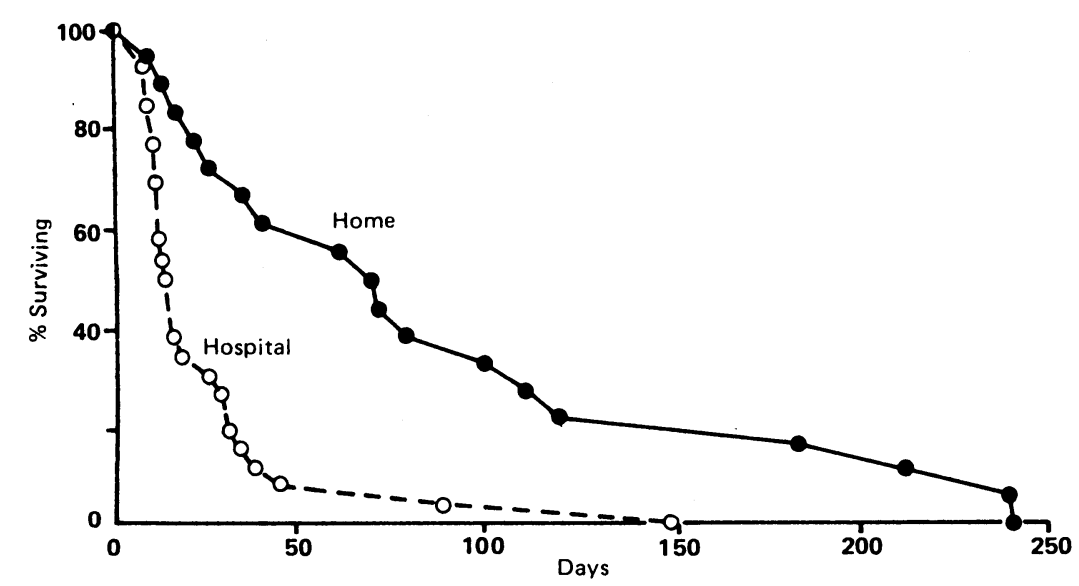

Survival of babies with spina bifida kept in hospital and taken home

PARENTS' PARTICIPATION IN CARE

Hospital care - Twenty six babies had been cared for in hospital until they died, and one had gone home for just one night. Six of these had been visited by only one parent, 10 had never been held by the mother, and seven had never been held by the father. More than half of them had never been given a feed by either parent. Parents were asked about the kind of life experienced by their children. Twenty one parents who had rarely, if ever, visited their babies were compared with 24 who recalled having had a greater interaction. They considered that when they had taken part in their baby's care the baby had enjoyed a better life (table I).

Home care-Eighteen babies had gone home for palliative care; their parents rated them as having had a better quality of life than did the parents of babies who never went home (table II). They had lived longer than those who had stayed in hospital (figure). Once at home most babies had spent over half of the rest of their lives there.

Palliative and terminal care-All 44 babies had died before their first birthday. Only a quarter of them had required treatment - for example, analgesics and anticonvulsants - though half had been given drugs terminally. Six of the 18 babies taken home had died there, the remainder having been admitted terminally because of worrying symptoms. Of the 38 babies who had died in hospital, 25 had never been home at all and 29 had died without a member of the family present, though four of these had spent time at home. The six who had died at home had been ill and causing concern, but each death had been peaceful and, with one exception, both parents had been present.

Support for the parents-Parents were asked how well supported they had felt by the hospital, general practitioner, community nurses, and their family. For families whose babies never went home most support had come from the hospital and community nurses with less help from the general practitioner and extended family (table III). When babies went home

TABLE III-Quality of support for families of babies with spina bifida as perceived by parents

Baby in hospital Baby at home Total

\begin{tabular}{|c|c|c|c|c|}
\hline Hospital staff & $\begin{array}{l}\text { Good } \\
\text { Poor }\end{array}$ & $\begin{array}{l}28 \\
17\end{array}$ & $\begin{array}{r}27 \\
8\end{array}$ & $\begin{array}{l}55 \\
25\end{array}$ \\
\hline General practitioner & $\begin{array}{l}\text { Good } \\
\text { Poor }\end{array}$ & $\begin{array}{r}9 \\
36\end{array}$ & $\begin{array}{l}15 \\
20\end{array}$ & $\begin{array}{l}24 \\
56\end{array}$ \\
\hline Community nurses & $\begin{array}{l}\text { Good } \\
\text { Poor }\end{array}$ & $\begin{array}{l}15 \\
30\end{array}$ & $\begin{array}{r}29 \\
6\end{array}$ & $\begin{array}{l}44 \\
36\end{array}$ \\
\hline Family & $\begin{array}{l}\text { Good } \\
\text { Poor }\end{array}$ & $\begin{array}{l}17 \\
28\end{array}$ & $\begin{array}{l}23 \\
12\end{array}$ & $\begin{array}{l}40 \\
40\end{array}$ \\
\hline
\end{tabular}

the amount of support offered by the general practitioner and the rest of the family had increased considerably, with even more from the community nurses. The hospital, by allowing open access, had maintained much the same support for babies at home as for those in hospital.

Effect on parents' personalities-Nearly half of the parents thought that the experience had affected their personalities (table IV), and two thirds of those thought that the effect had been positive. Only one

TABLE IV - Parents' perception of effect on their personalities of their baby's life and death

\begin{tabular}{lccc}
\hline & Baby in hospital & Baby at home & Total \\
\hline No effect & 18 & 23 & 41 \\
Positive effect & 13 & 10 & 23 \\
Negative effect & 11 & 1 & 12 \\
No opinion given & 3 & 1 & 4
\end{tabular}


TABLE V-Parents' response to question "Has any good thing come out of your experience?"

\begin{tabular}{lcc}
\hline Response & \multicolumn{2}{c}{$\begin{array}{c}\text { Baby in Baby at } \\
\text { hospital }\end{array}$} \\
$\begin{array}{lcc}\text { home } \\
\text { Yes }\end{array}$ & 22 & 23 \\
No & 20 & 11 \\
Don't know & 3 & 1 \\
\hline Total & 45 & 35 \\
\hline
\end{tabular}

whose baby had been nursed at home reported a negative effect in contrast to 11 whose babies had stayed in hospital. When asked directly whether anything positive had come out of their experience 45 of the 80 parents thought that it had, and there was no difference between home and hospital groups (table V).

\section{RESIDUAL GRIEF}

The interviews took place five to 14 years after the deaths of the babies, a time during which hospita policy changed to home care being the norm. 'Table VI shows the parents' emotions according to the year of their baby's birth using the scoring system described above and includes the two fathers who were too upset to be interviewed.

TABLE VI - Parents' emotions when questioned in 1985-6 according to year of baby's birth. Score $1=$ sad and angry to $5=$ happy and serene

\begin{tabular}{|c|c|c|c|c|c|}
\hline \multirow[b]{3}{*}{ Emotional score } & \multicolumn{5}{|c|}{ Year of birth } \\
\hline & \multirow{2}{*}{$\frac{1972-5}{\text { Hospital }}$} & \multicolumn{2}{|c|}{$1976-9$} & \multicolumn{2}{|c|}{$1980-1$} \\
\hline & & Hospital & Home & Hospital & Home \\
\hline 5 & 1 & & 5 & & \\
\hline 4 & 4 & 1 & 1 & & 8 \\
\hline 3 & 10 & 3 & 1 & 2 & 6 \\
\hline 2 & 10 & 7 & 4 & & 9 \\
\hline 1 & $3^{\star}$ & $6^{\star}$ & 1 & & \\
\hline Total & 28 & 17 & 12 & 2 & 23 \\
\hline
\end{tabular}

$\star$ Includes one father who evaded interview.

Parents of all babies-Only 20 of the 82 parents were fairly happy (scoring 4 or 5). Fourteen of these had taken their baby home (out of a total of 35 who had done so), whereas 41 of the 47 who had not taken their baby home were fairly unhappy (scoring 1-3). This difference was confirmed by comparing the 28 parents of babies born before 1976, who had not been given a choice about hospital care, with the 54 families of babies born during 1976-81, who had had the option of home care. Only five parents of babies born before 1976 scored 4 or 5 compared with 15 of babies born during 1976-81.

Parents of babies born during 1976-9-Home care gradually increased during this period. About three quarters of the parents from these years $(22 / 29)$ remained less than happy, with scores of 1-3. When home and hospital care were compared half of the parents who had taken their baby home scored 4 or 5 whereas 16 out of 17 who had not taken their baby home scored 1-3.

Parents of babies born during 1980-1 - By this time we expected more satisfaction but did not find it. Though all but two of the 25 parents had cared for their baby at home, the scores were $2-4$. The figures were too small, however, to distinguish differences between home and hospital care, and bereavement in this group was most recent.

\section{PARENTS' COMMENTS}

At the end of each interview the parents were asked what advice they would give to other parents of babies with inoperable spina bifida. All parents who had taken their baby home advised others to do the same, and despite their own hurt nearly half of the parents whose babies had stayed in hospital advised others either to take their baby home or to take part in the baby's care in hospital.

\section{Discussion}

The main findings of this investigation are that most of the parents had wanted to be included in the care of their handicapped baby and that sadness was more profound when these views had been ignored. As both professional and public opinion tends to confuse the value of life with its quality these families give a timely reminder that relationships can be rich even when the outlook is poor and that each life can be of value though quality may vary widely.

The understanding of perinatal psychology has advanced in the past two decades. Initially badly handicapped babies with spina bifida who were unlikely to benefit from early operation often entered a medical limbo and were thought of more as problems than as having personal needs. ${ }^{2}$ Discussions and decisions about them took place in their absence, which was symbolic of the prevailing dismissive attitude towards them. Subsequently both staff and parents have had to learn that to deny reality is not the answer to bereavement. Despite their sadness for what might have been most parents are now known to be helped rather than hurt by contact with their handicapped baby. ${ }^{34}$ When expectation of life is reduced to days, weeks, or months it becomes more rather than less important to give the parents and child time together. Terminal care, even for babies, should include care for the whole person not merely for the physical state.

Some frail babies respond poorly to their parents, and in such cases more support is needed for the families. In other cases, if due attention is paid to the baby's personal needs for interaction and relief from discomfort normal life not only is possible but will also be prolonged. As one mother commented, "Love kept her alive." Such remarks were made with pleasure by parents, who clearly did not share the veiled dismay sometimes felt by professional onlookers.

From 1972 to 1975 , when none of the babies went home for care, the only parent to express ultimate serenity was a mother who had made the hospital as much like home as she could. Many of the personal stories recounted from this period reflected the staff's confusion about how to behave over babies for whom there was no cure. Often there was paternalism towards the parents, which, though kindly meant, spelt to them rejection of their parenthood. Few parents understood their child's palliative care and even fewer took part in the terminal stages, often being notified by telephone that their baby had died. Even then their need to see for themselves was rarely recognised and most were left with chronic grief and even bitterness.

From 1976 to 1979 attitudes changed after a clergyman and his wife behaved towards their handicapped baby as they would have done to a normal child. He was breast fed and taken home. Slowly this was seen as a pattern to be encouraged. Some babies still needed treatment, even at home, titrated against physical symptoms, but this was simply to enhance their quality of life. Parents subsequently thought that the child's life had probably been happier and that they themselves were left considerably happier by this policy.

By 1981 over $90 \%$ of these severely handicapped babies were going home. Contrary to expectations, however, we found that most parents were still not happy. These were the parents interviewed most recently after their bereavement, though still five to six years after it. This could indicate that it takes longer to recover from bereavement than is customarily believed. A contributory factor to this prolonged pain of bereavement may be that home care resulted in the babies having longer and more rewarding lives. We have the paradox of the parents expressing greater satisfaction in having cared for their baby but also experiencing greater sadness when the baby died.

Parents whose baby was distanced from them in hospital felt correspondingly distant from most of their potential supporters in the family and community, and 
some felt diminished by their experience. Over half of all parents interviewed, despite their sad experience, believed that their own personalities had been affected for the good, citing, for example, an increase in patience and a recognition that people matter more than things. More of those who had cared for their baby considered that they had experienced personal growth and that the baby's short life had enriched a wide circle of relationships, both personal and professional. This brought these parents unanimously to agree that home care was the better option.

Medical staff may still react by saying that it is kinder to keep parents uninvolved and for disabled babies to die quickly and quietly. This is treating parents like children, ignoring the baby's personal needs, and also now denying the evidence. Parents need to be encouraged in their parenting, which includes being helped to see things from the child's point of view. As they come to terms with the problems they need more support than has sometimes been given them in the past. ${ }^{6}$ Some personal stories accentuated the need for special help for fathers and siblings in a bereaved family ${ }^{78}$ Hospital and community staff need to learn counselling skills as well as technical competence. This may mean that they need to be counselled themselves, starting with the reminder that parents may find it better to have loved and lost a baby than never to have been close to the child at all. The interviewer was repeatedly told how helpful her visit would have been had it taken place years earlier.

We are grateful for a grant from the Association for Spina Bifida and Hydrocephalus, without which this survey could not have been undertaken. We also thank Drs Stephen Richardson and Anne Griffiths for collecting basic data, Iris Roscoe for retyping the manuscript. Most of all we thank all the parents who shared such moving personal stories with us and thereby taught us how to improve the service for handicapped babies.

A fuller account of this survey including details of the questionnaire, the interviewer's methods, and a more detailed discussion of the conclusions is available from the Association for Spina Bifida and Hydrocephalus.

1 Richardson SA, Goodall J. Trends in the management of spina bifida babies, 1971-81: home care for the non-surgical group. Maternal and Child Health 1984;9:252-7.

2 Lorber J. Results of treatment of myelomeningocoele. An analysis of 524 unselected cases with special reference to possible selection for treatment. unselected cases with special reference

3 Solnit AJ, Stark MH. Mourning and the birth of a defective child. Psychoanal Study Child 1961;16:523-37.

4 Standish L. The loss of a baby. Lancet 1982; ;:611-2.

Saunders C, ed. The management of terminal disease. London: Edward Arnold, 1984.

6 Drotar D, Baskiewicz A, Irvin N, Kennell J, Klaus M. The adaptation of parents to the birth of an infant with a congenital malformation: a hypothetical model. Pediatrics 1975;56:710-7.

7 Pincus L. Death and the family: the importance of mourning. London: Faber and Faber, 1976.

8 Pettle MSA, Lansdowne RG. Adjustment to the death of a sibling. Arch Dis Child 1986;61:278-83.

(Accepted 8 August 1988)

\author{
K R Fogelman, O Manor
}

\begin{abstract}
Follow up analyses of data on the 1958 cohort from the national child development study have shown that the association of smoking in pregnancy with physical and intellectual development diverges between the sexes at age 16, no longer being significantly associated with height in girls. These studies, however, have emphasised that the differences in outcome are small and may be explained by other factors. The analyses have taken account of birth weight and have therefore examined the effects of smoking on subsequent development in addition to this variable. To assess the importance of smoking on development in early adult life and whether the effect is independent of birth weight data from the 1958 cohort at age 23 were analysed. Only weak evidence for a relation between smoking in pregnancy and self reported height of the offspring was apparent once social class, size of family, mothers' height, and birth weight for gestational age were taken into account. After omission of birth weight from the analyses, however, the average difference in height between subjects whose mothers smoked 20 cigarettes a day or more during the second half of pregnancy and those whose mothers did not was 0.93 $\mathrm{cm}$ in men and $1.83 \mathrm{~cm}$ in women. A strong association was also evident with the highest qualification achieved by subjects at this age, suggesting a long term relation between smoking in pregnancy and the intellectual development of the offspring.
\end{abstract}

\section{Introduction}

A causal relation between smoking in pregnancy and the survival and birth weight of the baby is generally accepted. Most of the evidence has come from national cohort studies, in particular the national child development study, of people born in $1958^{12}$ and the 1970 cohort study, the child health and education study. ${ }^{3}$ Early analyses of data from the national child development study, for example, showed that smoking 10 cigarettes a day or more in the second half of pregnancy increased the perinatal mortality rate by $28 \%$ and reduced birth weight by a mean of $170 \mathrm{~g}$ compared with no smoking ${ }^{4}$ and that these results were not changed when possible mediating factors such as social class, maternal age, and parity were allowed for. ${ }^{5}$ Similar results have been reported for the cohort born 12 years later. ${ }^{6}$

Subsequently, a series of follow up studies have examined the development of the children in the national child development study whose mothers had smoked during pregnancy. Smoking was significantly related to the children's height and their attainments in reading and mathematics at the ages of 7 and $11 .{ }^{178} \mathrm{By}$ contrast with the perinatal findings, however, these relations were reduced when possible mediating factors were taken into account, although they were still significant. At age 16 similar results were obtained for attainments in reading and mathematics, but the association of smoking with height in girls had decreased and was no longer significant. ${ }^{9}$ In boys the mean difference in height between the children of nonsmoking mothers and mothers who had smoked 10 cigarettes a day or more $(0.88 \mathrm{~cm})$ was close to the comparable contrast at age 11 . The difference between the sexes was compatible with an association between the mothers' smoking and the rate of the children's growth or their growth to puberty but not between smoking and their eventual adult height (which is achieved by almost all girls by the age of 16). These findings, however, mainly emphasised that 